\title{
Mentor of the Month Series: Laparoscopic Training in the United States
}

\author{
Ruchir Puri, MD ${ }^{1} \cdot$ Horacio J. Asbun, MD $^{2}$ \\ Received: 31 October 2018 / Accepted: 13 November 2018 /Published online: 3 December 2018 \\ (C) 2018 The Society for Surgery of the Alimentary Tract
}

\section{Introduction}

Dr. Horacio J. Asbun is the Chief of Hepatobiliary and Pancreas Surgery at Miami Cancer Institute. He was born and raised in La Paz, Bolivia, and attended medical school at the University of Chile. He did his initial surgical training for two years in Spain followed by a surgical oncology postdoctoral fellowship at the University of California in San Diego. He subsequently completed a general surgical residency at Kern Medical Center in Bakersfield, CA, and a gastrointestinal and hepatopancreatobiliary (HPB) surgery fellowship at the Lahey Clinic in Burlington, MA. Prior to his current appointment, he served as the Chief of Hepatobiliary Surgery at Mayo Clinic in Jacksonville and Professor of Surgery at Mayo Medical School.

Dr. Asbun has numerous honors and awards and serves in many national and international boards and organizations. Most notably, however, is that Dr. Asbun is a leader in laparoscopic HPB surgery and serves as the vice president of Society of American Gastrointestinal and Endoscopic Surgeons (SAGES) and the Editor-in-Chief of the American College of Surgeons Video Atlas. Given his technical expertise and reputation in minimallyinvasive surgery, he joins us today as our "Mentor of the Month" to discuss the role of minimally invasive surgical training in the United States today. He is interviewed by Dr. Ruchir Puri, Assistant Professor of Surgery at the University of Florida COM, Jacksonville, and an active member of the Society for Surgery of the Alimentary Tract Resident and Fellow Education Committee.

Ruchir Puri, MD

ruchir.puri@jax.ufl.edu

1 Department of Surgery, University of Florida COM, 653 W 8th St., Jacksonville, FL 32209, USA

2 Chief of Hepatobiliary and Pancreas Surgery, Miami Cancer Institute, Miami, FL, USA
The full interview which has been transcribed and modified for print can be viewed on http://ssat.com/residents/ mentor/?dID=33.

Question 1-Could you tell us how laparoscopic cholecystectomy started in the US?

Answer 1-Laparoscopic surgery has been around since the 1800 s but the real revolution came in the late 1980s. Laparoscopic Cholecystectomy was first performed by the German surgeon Dr. Erich Muhe who was initially discredited, but later vindicated. It was then performed in France and subsequently in the United States (US). The first US cholecystectomy was performed by Drs. J. Barry McKernan and William B. Saye in Marietta, Georgia and subsequently by Drs. Eddie Joe Reddick and Douglas Olsen in Nashville, Tennessee. They then mastered and taught their technique, and I was fortunate enough to work with them. I applied for an elective rotation and subsequently accompanied them on numerous courses. I was a resident at that time, and it was a great opportunity since I saw the evolution of laparoscopic surgery from the earliest stages to where we are now, performing routine laparoscopic operations such as Nissen fundoplications, colectomies, etc. The laparoscopic revolution implied that we could do things differently and we started to question all the things we were taught in the past. These were exciting times, but they were also tough times, because the challenges were how to regulate this and how best to ensure that patients were not harmed. Many of us struggled to learn novel techniques such as adrenalectomies. The first adrenalectomy I did was after talking to a few surgeons who were doing the procedure. Also, there seemed to always be a race to becoming the first person perform a procedure. While it was exciting and fascinating, there was real need to regulate the field. What was "I" going to do and what are the ethics of doing what I am doing. Though it sounds clichéd, you had to ask yourself what was best for the patient. Every time I tried to do something novel I asked myself "would I do this on a relative of mine?" This philosophy has guided me for many years. We performed a variety of procedures. New technologies emerged and there were several pioneers who emerged 
during that time. It is also fascinating that, conversely, several surgeons stated that laparoscopy was a passing fad. I never imagined that we would be doing these complex procedures that we are doing today, but it has certainly been a good ride and I am glad I was able to be a part of it.

Question 2-That leads me to the next question. You are one of the pioneers of laparoscopic pancreatic surgery. What is the future of this field as there seems to be ongoing debate related to it?

Answer 2-You are right, I think the debate still persists. In summary the laparoscopic approach to the pancreas is here to stay, there is no doubt about that. The real questions are how much and by whom. In terms of procedures on the left side of the pancreas or distal pancreatectomy, there is no doubt that there are several advantages laparoscopically, although this has not been proven in a prospective randomized control trial. It sounds biased but several of us feel that we cannot ethically conduct such a study. In terms of right-sided pancreatectomy or Whipple pancreaticoduodenectomy, I am not sure. I feel that it is here to stay but I do not know how many surgeons are going to be performing it. The progress we have seen over the last few years in terms of technology such as 3D visualization, robotic surgery, and better instrumentation has made the procedure more feasible. There is no doubt that surgeons who have reached a level of confidence and comfort with the procedure have proven non-inferiority compared with the open equivalent, and, in some cases, that it may be better. The limiting factor will be how well we can teach the procedure. I feel the laparoscopic Whipple started too early and is, in part, the reason the procedure has earned a bad reputation.

Question 3-How has the surgical training evolved since you were a resident?

Answer 3-There are many aspects of surgical training that are better than they were in the past. In the past, attendings were treated like "gods" and we blindly did whatever they said; you may laugh and think it is still the same, but it's not! The collegiality and professionalism has improved. I believe that there is heightened awareness to improve equality for women and minorities. These aspects play an important role in training and those are the positive aspects. I have mixed feelings about duty-hour restrictions. In some respects, I feel it's great and the hours are more humane. However, one thing that worries me is that I see many of our trainees are losing a sense of "ownership" of the patient. In the past, if you were in surgery, you owned the patient and followed them throughout their stay. Today it's extremely difficult to maintain that level of ownership of the patient. I would encourage all the trainees to make an effort to "own" their patients throughout their journey. I feel that surgical training is going to change again. It will likely be less generalized and more specific and specialized in areas such as foregut, HPB or colorectal surgery, etc. We will probably see a shortened residency training in general surgery with a couple of years of specialty focus or interest.

Question 4-What are the challenges that surgical residents and faculty face today?

Answer 4-There are several challenges. The main one is the number of administrative obligations we have. The amount of "paperwork," documentation, and emails is overwhelming. I do not feel that subsequent generations will put up with what we are putting up with today. I feel it will have to change in that we have to go back and use these tools so that they are working for us, not against us! Today we are working constantly to catch up with emails, telephone calls, and messages. This has created a situation where we have less time to mentor each other. To be able to affect someone's professional career in a positive way is something that is so beautiful and exciting. We need to find a balance to allow technology to work in our favor.

Question 5-What enabled you to get to where you are now and what advice do you have for our young surgeons?

Answer 5-Thank you for this opportunity. I am honored that one of my former trainees felt that I am someone who can help with this interview. I have been very fortunate. I came from an under-developed country but what I think is important is not the cards you are dealt, but what you do with them. I am a believer that everyone has opportunities presented to them. The key is to recognize that an opportunity, grab it, and run with it. Sometimes you think it is an opportunity and it's not, but if you do not try, you will never know. The second thing I would add is try not to ascend at the expense of others, as this will catch up with you at some point. Be as honest as you can with your practice and what you tell other people. Above all, do not say "I'm trying my best" because you do not know what your best is until you try beyond your best. Have passion for what you do, understand there will be ups and downs, work hard, and think about everyone not just yourself.

\section{Publisher's Note}

Springer Nature remains neutral with regard to jurisdictional claims in published maps and institutional affiliations. 